Portland State University

PDXScholar

\title{
"I Get Knocked Down but I Get up Again": Integrative Frameworks for Studying the Development of Motivational Resilience in School
}

\author{
Ellen Skinner \\ Portland State University, ellen.skinner@pdx.edu \\ Jennifer Pitzer Graham \\ Institute for Research and Reform in Education \\ Heather Anne Brule \\ Portland State University, heather.brule@gmail.com \\ Nicolette P. Rickert \\ Portland State University, nrickert@pdx.edu \\ Thomas Kindermann \\ Portland State University, kindermannt@pdx.edu \\ Follow this and additional works at: https://pdxscholar.library.pdx.edu/psy_fac \\ Part of the Educational Psychology Commons \\ Let us know how access to this document benefits you.
}

\section{Citation Details}

Skinner, E., Graham, J. P., Brule, H., Rickert, N., \& Kindermann, T. (2020). “I get knocked down but I get up again": Integrative frameworks for studying the development of motivational resilience in school. International Journal of Behavioral Development, 0165025420924122.

This Article is brought to you for free and open access. It has been accepted for inclusion in Psychology Faculty Publications and Presentations by an authorized administrator of PDXScholar. Please contact us if we can make this document more accessible: pdxscholar@pdx.edu. 


\title{
"I get knocked down but I get up again": Integrative frameworks for studying the development of motivational resilience in school
}

\author{
Ellen A. Skinner, '๑ Jennifer Pitzer Graham, ${ }^{2}$ Heather Brule, \\ Nicolette Rickert, '® and Thomas A. Kindermann'
}

\begin{abstract}
Many subareas share a common interest in students' motivational resilience, defined broadly as patterns of action that allow students to constructively deal with, overcome, recover, and learn from encounters with academic obstacles and failures. However, research in each of these areas often progresses in relative isolation, and studies rarely utilize developmental or social-contextual approaches. As a result, we do not yet have a clear understanding of how to help children and adolescents develop a rich and flexible repertoire of tools to deal productively with everyday academic challenges and difficulties. In this article, we knit together these disparate areas of work to create an integrated developmental and social-contextual framework that can guide the future study of these processes. First, we summarize nine areas of work that focus on students' actions on the ground when they encounter academic difficulties: academic resilience, mastery versus helplessness, engagement and re-engagement, academic coping, self-regulated learning, adaptive help seeking, emotion regulation, and buoyancy as well as tenacity, perseverance, and productive persistence. In each area, we highlight work that is explicitly developmental and that depicts key social-contextual factors that shape motivational resilience. Second, we sketch an overarching social-contextual and developmental framework that holds a place for each of these processes. Third, we identify multiple areas where cross-fertilization among researchers can contribute to improved educational practice and study of the development of motivational resilience. An overarching goal of this article (and the special section more generally) is to take first steps toward "field building" on this crucial topic.
\end{abstract}

\section{Keywords}

Academic resilience, academic coping, everyday resilience, self-regulated learning, adaptive help seeking, academic engagement, academic buoyancy, persistence, tenacity, academic development

If students are to reach their educational potential, they must learn how to deal constructively with the challenges, setbacks, and failures they encounter daily in their academic work. This conviction is shared by researchers who study a range of social, developmental, and educational processes, including academic resilience, mastery versus helplessness, engagement and re-engagement, academic coping, self-regulated learning, adaptive help seeking, emotion regulation, and buoyancy, as well as tenacity, perseverance, and productive persistence. However, research on each of these topics often progresses in relative isolation from work in other areas, and studies rarely utilize developmental or social-contextual approaches. As a result, we do not yet have a full understanding of how to help children and adolescents develop a rich and flexible repertoire of tools to deal productively with the challenges and difficulties they encounter every day in their schoolwork.

The goals of this article are threefold. First, we summarize work from many subareas within educational and developmental science in order to underscore the common ground they share in studying students' motivational resilience, defined broadly as patterns of action that allow students to deal constructively with, overcome, recover, and learn from encounters with academic obstacles and failures (Martin \& Marsh, 2009; Skinner \& Pitzer, 2012; Yeager \& Dweck, 2012). These approaches focus on actual responses (including emotions and goal-directed behaviors) that emerge on the ground as part of episodes during which students are dealing with academic problems. Patterns of action can be contrasted with the belief systems, motivations, or skill sets that underlie these responses. In each area, we highlight conceptual and empirical work that is explicitly (1) developmental, in that it relies on developmental conceptualizations, provides process-oriented accounts, or describes age-graded normative or differential trajectories; and (2) social-contextual, in that it identifies the interpersonal and environmental factors that contribute to the development of motivational resilience and its opposite, motivational vulnerability. Second, we sketch an overarching social-contextual and developmental framework that holds a place for work on each of these topics. Third, we suggest several places where cross-fertilization among research areas can contribute to better educational practice

\footnotetext{
I Portland State University, USA

${ }^{2}$ Institute for Research and Reform in Education, USA
}

\section{Corresponding author:}

Ellen A. Skinner, Department of Psychology, Portland State University, PO Box 75I, Portland, OR 97207, USA.

Email: skinnere@pdx.edu 
and more focused study of the development of motivational resilience. We view this article and the special section more generally as first steps toward "field building" on this crucial topic.

\section{Research Focusing on Processes of Motivational Resilience and Vulnerability}

Nine areas of research were identified that have in common a focus on motivational resilience and vulnerability. The use of these umbrella terms implies that all of these processes can be considered parts of a larger motivational system that becomes active when students encounter obstacles and setbacks. In contrast to the larger fields of coping and resilience, which typically focus on small subgroups of individuals exposed to traumatic stress or severe life adversity, researchers who study "everyday coping" (Wolchik \& Sandler, 1997) and "everyday resilience" (Martin, 2013) posit that many events common to daily life require coping and that individuals' everyday resilience in the face of these "daily hassles" may cumulatively foster positive functioning and growth (Aldwin, 2007; Martin \& Marsh, 2009; Masten, 2007; Skinner \& ZimmerGembeck, 2007). Over time, these experiences should promote the development of resilience resources, such as confidence, regulatory "muscles," or the capacity to rely on others, that may eventually allow students to deal more effectively with larger and more stressful life events. Definitions of the key constructs from these nine approaches appear in Tables 1 and 2, along with the kinds of academic problems examined in each.

\section{Academic Resilience}

The study of motivational resilience is embedded in the larger area of academic resilience, which focuses primarily on processes that allow students to succeed in school, despite the presence of significant adversity or risk factors that typically lead to poor academic outcomes (Martin \& Marsh, 2006, 2009; Wang et al., 1994). Although research considers a variety of types of adversity, ranging from experiences with harsh parenting to child maltreatment, homelessness, and foster care, the risk factors studied most commonly are membership in marginalized socioeconomic, racial/ethnic minority, and immigrant groups (see Tudor \& Spray, 2017; Waxman et al., 2003). A few studies examine risk factors that are explicitly academic, such as poor prior performance, doubts about completing school, grade retention, or dropout. In general, however, such studies do not consider patterns of action embedded in everyday academic struggles (cf. Martin \& Marsh, 2006). Instead, they focus on the personal, interpersonal, and environmental/systemic resources and liabilities that can help explain why some students continue to show serious academic problems whereas others recover.

Although conceptualizations are explicitly developmental, in that resilience manifests as a trajectory that is more positive than expected given the constellation of risk factors, relatively little research actually examines age differences or developmental trends in academic resilience. Some studies do document trends in the probability of recovery from risk, revealing that resilience is less likely when risk factors persist over time or are present during certain developmental windows (such as the transition to high school). As a whole, this work is explicitly social-contextual, in that it considers protective factors from a variety of levels, including interpersonal and environmental resources.

\section{Mastery, Helplessness, and Mindsets}

A mastery orientation, defined as "an intrinsic desire to master one's environment” (Jennings \& Dietz, 2003, p. 295), is characterized by effort exertion and preference for challenge. When faced with obstacles, mastery-oriented students tend to persist, explore alternative strategies, and actively guide and encourage themselves (Dweck, 1986; Harter, 1981; Thomas, 1989). In contrast, a learned helplessness orientation, defined as "a negative emotional and cognitive reaction in individuals who perceive that they have no influence over the outcome of an event" (Thomas, 1989, p. 236), is characterized by discouragement, desistence, avoidance of challenge, and expectations of failure in the face of difficulties and setbacks (Dweck, 1986; Mark, 1983; Thomas, 1989).

As the study of learned helplessness shifted from animals to humans in the late $1970 \mathrm{~s}$, researchers began to examine the cognitive underpinnings of helpless patterns of action, focusing first on perceived control and attribution theory (Dweck \& Wortman, 1982), then achievement goal orientations (Dweck \& Leggett, 1998), and most recently, mindsets (Dweck, 2008). Current work distinguishes a growth mindset, in which ability is seen as a malleable characteristic that can be changed with effort, from a fixed mindset, in which ability is viewed as an unchangeable trait (Yeager \& Dweck, 2012). Although mastery and learned helplessness orientations have been documented from preschool to college (Mark, 1983), little work has specifically examined how these orientations develop. However, educational interventions have demonstrated that growth mindsets can be promoted through a variety of interpersonal and pedagogical strategies, for example, by teaching students about neuroplasticity, praising them for their efforts, and allowing them to repeat assignments until they master the material (Yeager \& Dweck, 2012).

\section{Engagement and Re-Engagement}

Research has converged on academic engagement-students' ongoing, active, attentive, energized involvement and persistence in learning activities (Jimerson et al., 2003) - as a key to educational success (Christenson et al., 2012; Upadyaya \& Salmela-Aro, 2013). Engagement is a strong predictor of learning, achievement, and retention (e.g., Appleton et al., 2008; Janosz et al., 2008) and plays a protective role against school dropout, gang involvement, substance use, and other risky behaviors (e.g., Blondal \& Adalbjarnardottir, 2012; Li \& Lerner, 2011). Moreover, engagement is malleable (Appleton et al., 2008; Fredricks et al., 2004), making it a prime target for researchers and educators looking for practical levers to bolster students' educational functioning.

When children and adolescents encounter stressors and problems in school, these experiences can exert a downward pressure on motivation. During these encounters, engagement provides energy, momentum, and stamina to sustain and guide students, and when highly engaged students run into trouble, they are unlikely to give up. Instead, they typically look for ways to continue, responding with actions that enable them to obtain the strategies, information, and energy needed for renewed task involvement. In contrast, when students who are already disaffected encounter challenges, the low energy and emotional reactivity that characterize disaffection can elicit 
Table I. Constructs that Tap Aspects of Students' Motivational Resilience or Vulnerability.

\begin{tabular}{ll}
\hline Construct & Definition \\
\hline Academic resilience & "[T]he heightened likelihood of success in school and in other life accomplishments, despite environmental \\
adversities, brought about by early traits, conditions, and experiences" (Wang et al., 1994, p. 46). & $\begin{array}{c}\text { Patterns of action in the face of challenges and obstacles characterized by either mastery (preference for } \\
\text { challenge, effort, optimism, and persistence) or helplessness (discouragement, passivity, pessimism, and } \\
\text { Mastery, helplessness, and mindsets }\end{array}$
\end{tabular}

- Growth mindset: Individuals' beliefs that their most basic abilities can be developed through dedication and hard work (Dweck, 2008).

- Fixed mindset: Individuals' beliefs that their basic qualities, like intelligence or talent, are simply fixed and unchangeable traits (Dweck, 2008).

Engagement and re-engagement

Engagement: Students' ongoing, active, enthusiastic, and energized involvement in learning tasks as seen in behavioral, emotional, and cognitive responses.

Re-engagement: Students' actions in the face of obstacles and challenges that lead back to a state of ongoing engagement rather than giving up.

Academic coping

How students deal with the academic challenges, obstacles, and setbacks they encounter daily.

- Adaptive ways include problem-solving/strategizing, seeking instrumental help, comfort seeking, selfreliance/self-encouragement, and accommodation/commitment.

- Maladaptive ways include escape/avoidance, helplessness, social isolation/concealment, delegation/selfpity, self-blame/rumination, and blaming others.

Self-regulated learning

"A constructive process whereby learners proactively monitor, control, and regulate their thoughts, feelings, and behaviors to achieve self-set learning goals" (Zusho, 2017).

- Commonly studied strategies include self-instruction, verbal elaboration, text comprehension monitoring, goal setting and planning, self-recording, self-evaluation, organization and transformation, information seeking, self-monitoring, environmental structuring, giving selfconsequences, rehearsing and memorizing, seeking social assistance, reviewing, metacognitive monitoring, strategic planning, time management (Zimmerman, 1990; Zimmerman \& Cleary, 2009).

Adaptive help seeking

Referring to resources outside of oneself to find information or strategies that will assist in accomplishing a task or solving a problem.

- Adaptive help seeking (instrumental/necessary): Autonomous requests for aid appropriately directed to a more competent helper in ways that produce information or strategies needed to continue the learning process independently.

- Avoidance of help: "[I]nstances when students know that they need help but do not seek it" (Ryan et al., 200I, p. 94).

- Executive help seeking (expedient/convenient/work avoidant/delegation): Asking for solutions or help that expedites task completion without genuine interest in learning.

Emotion regulation

"[T] he processes by which individuals influence which emotions they have, when they have them, and how they experience and express these emotions" (Gross, 1998, p. 275).

- Five families of processes: Situation selection, situation modification, attentional deployment, cognitive change, and response modulation.

- Strategies include acceptance, avoidance, problem-solving, reappraisal, rumination, and suppression.

- Intrinsic versus extrinsic: A person's attempts to influence their own emotions versus the emotions of others.

Buoyancy

Grit, academic tenacity, perseverance, productive persistence
Students' ability to deal with everyday academic setbacks and challenges (Martin \& Marsh, 2009).

Grit: Perseverance and passion for long-term goals (Duckworth et al., 2007).

Academic tenacity: " $[T]$ he mindsets and skills that allow students to look beyond short-term concerns to longer-term or higher-order goals, and withstand challenges and setbacks to persevere toward these goals" (Dweck et al., 2014, p. 4).

Academic perseverance: "[A] student's tendency to complete school assignments in a timely and thorough manner, to the best of one's ability, despite distractions, obstacles, or level of challenge" (Farrington et al., 2012, p. 9).

Productive persistence: The "tenacity and strategies to persist despite challenges" (Silva \& White, 2013, p.7). maladaptive ways of dealing with problems, including giving up. Recent research has focused on students' patterns of action following challenges and setbacks, distinguishing desistence from the kind of re-engagement that returns students to an energized motivational state with all its concomitant benefits (Pitzer \& Skinner, 2017).

Although the area largely focuses on individual differences, the study of engagement from a motivational perspective has a strong developmental bent, and longitudinal studies consistently document steady declines in students' engagement over time, with more pronounced downturns apparent over educational transitions (Wigfield et al., 2015). Work on engagement as a whole is explicitly socially contextual and has identified a variety of factors at home, at school, and in the peer group that shape the development of engagement, such as the quality of interpersonal relationships, warmth and involvement, pedagogical practices, goal orientations, classroom structures, autonomy support, and the nature of academic work. 
Table 2. The Kinds of Academic Problems Examined in Areas of Research Related to Students' Motivational Resilience or Vulnerability.

\begin{tabular}{|c|c|c|}
\hline Area & Problems & Examples of Problems Encountered \\
\hline Academic resilience & $\begin{array}{l}\text { Exposure to proximal or distal } \\
\text { risk factors or adversity }\end{array}$ & $\begin{array}{l}\text { Adversity: Disturbances to the function or viability of a system; experiences that } \\
\text { threaten adaptation or development. Examples: Poverty, homelessness, child } \\
\text { maltreatment, political conflict, natural disaster. } \\
\text { Risk factor: A measurable characteristic in a group of individuals or their situation that } \\
\text { predicts a negative outcome on a specific outcome or criterion. Examples: } \\
\text { Premature birth, parental divorce, poverty, parental mental illness, child } \\
\text { maltreatment. } \\
\text { - Proximal risk: Risk factors experienced directly by the child. Examples: } \\
\text { - Witnessing violence, associating with delinquent peers. } \\
\text { - Distal risk: Risk arising from a child's ecological context but mediated through } \\
\text { more proximal processes. Examples: High community crime rate, inaccessible } \\
\text { health care, recession (Wright et al., } 2013 \text {, p. I7). } \\
\text { Academic risk factors, such as first-generation college student status, low performance, } \\
\text { grade retention, dropout. }\end{array}$ \\
\hline $\begin{array}{l}\text { Mastery, helplessness, and } \\
\text { mindsets }\end{array}$ & Academic difficulties & Non-contingency, challenge, difficulty, failure. \\
\hline Engagement and re-engagement & Academic stressors & $\begin{array}{l}\text { Encounter with difficult problem or question. } \\
\text { Poor performance on a test or assignment. } \\
\text { Difficulty understanding something. }\end{array}$ \\
\hline Academic coping & Academic stressors & $\begin{array}{l}\text { General: "Something stressful with school work," "something bad happens at school," } \\
\text { academic difficulties. } \\
\text { Demanding schoolwork/homework: School-related challenges, problems completing } \\
\text { homework, too much schoolwork/homework, difficult or boring work. } \\
\text { Classroom: Can't answer a question in class, failure in the classroom, have trouble with } \\
\text { a subject. } \\
\text { Exams: Impending exam, can't organize self to study, studying and taking tests, major } \\
\text { final exam, failing an exam. } \\
\text { Poor academic performance: Difficulty learning, bad grade, report cards. } \\
\text { Trouble: Getting in trouble at school. } \\
\text { Transitions: List of stressors related to school (e.g., junior high) transitions. } \\
\text { Dissatisfaction: Unsatisfied with personal competencies. }\end{array}$ \\
\hline Self-regulated learning & Challenging academic material & Demanding or difficult learning environments. \\
\hline Adaptive help seeking & $\begin{array}{l}\text { Own resources are not } \\
\text { sufficient }\end{array}$ & $\begin{array}{l}\text { Perplexity: State of puzzlement or uncertainty arising from a discrepancy between } \\
\text { current personal knowledge and new information or expectations. } \\
\text { Ambiguity, Challenge, Difficulty. }\end{array}$ \\
\hline Emotion regulation & $\begin{array}{l}\text { Intense or distressing } \\
\text { emotions }\end{array}$ & $\begin{array}{l}\text { Emotional responses that are disruptive, attentionally demanding, or interfere with } \\
\text { one's goals. }\end{array}$ \\
\hline Buoyancy & Everyday academic setbacks & $\begin{array}{l}\text { Isolated poor grades/performance and resulting threats to confidence, competing } \\
\text { deadlines, daily stresses and pressures, minor conflicts with teachers. }\end{array}$ \\
\hline $\begin{array}{l}\text { Grit, academic tenacity, } \\
\text { perseverance, productive } \\
\text { persistence }\end{array}$ & Academic problems & Distractions, obstacles, setbacks, challenges. \\
\hline
\end{tabular}

\section{Academic Coping}

Emerging from the larger field of everyday coping (Wolchik \& Sandler, 1997), academic coping refers to the ways in which students deal with the challenges, obstacles, setbacks, and failures they encounter daily in their academic work. Research has identified a range of adaptive strategies (see Table 1), many of which are connected to higher academic performance, motivation, functioning, and persistence, as well as a range of maladaptive ways of coping (see Table 1) that are connected to poorer academic performance and functioning, including higher desistence, disaffection, and school-related burnout. Studies find that children and adolescents typically cope constructively, showing high levels of adaptive and low levels of maladaptive responses. Developmental research, consisting of about 15 studies, suggests that coping improves across elementary school and then shows a marked drop during early adolescence over the transition to middle school, followed by stability or some recovery during later adolescence (Skinner \& Saxton, 2019).

The bulk of research on academic coping focuses on individual differences, but developmental conceptualizations attempt to explicate how advances in specific underlying capacities (e.g., executive functions, emotional understanding, social skills) shape age-graded changes in coping from early childhood to late adolescence (e.g., Skinner \& Zimmer-Gembeck, 2016). These formulations also posit a reciprocal dynamic by pointing out that coping influences development: Episodes of effective coping can build students' capacities for dealing with future problems. As predictors of coping, studies focus largely on personal characteristics, such as self-efficacy, sense of belonging, and mastery goal orientations. Fewer studies examine the social-contextual factors that shape coping, but those that do find evidence that close and supportive relationships with 
mastery-oriented parents and teachers promote students' use of adaptive strategies.

\section{Self-Regulated Learning}

Self-regulated learning, defined as "self-generated thoughts, feelings, and actions that are planned and cyclically adapted to the attainment of personal goals" (Zimmerman \& Cleary, 2009, p. $247)$, is an active, dynamic process in which students set learning goals and use multiple strategies to control and monitor their cognition, motivation, behavior, and contexts in pursuit of those goals (see Table 1; Schunk \& Greene, 2017; Wolters \& Taylor, 2012; Zusho, 2017). Self-regulated learners are characterized as actively engaged in the learning process (Wolters \& Taylor, 2012; Zusho, 2017) and metacognitively aware of what they do and do not know. When they encounter difficult learning environments or face challenges, they are more likely to persist (Zimmerman, 1990) and to succeed academically (Zusho, 2017).

From a developmental view, self-regulated learning progresses from external to internal regulation: from initial observation to emulation of others to self-control and finally to self-regulation (Zimmerman \& Cleary, 2009). By adolescence, students demonstrate more refined self-regulated learning due to their ability to set appropriate proximal and distal goals, more accurately estimate competence, utilize more efficient and flexible cognitive strategies, delay gratification, and effectively regulate their affective responses to academic tasks (Wigfield et al., 2011). More recent models of self-regulated learning highlight the impact of antecedents such as personal characteristics (e.g., age, gender, ethnicity, self-efficacy, self-esteem) and contextual factors (e.g., academic tasks, instructional methods; Zusho, 2017). Thus, self-regulated learning has been viewed as a mediator between contextual or personal factors and academic performance, such that students higher in certain self-perceptions are likely to self-regulate more effectively, leading to greater learning and achievement (Wolters \& Taylor, 2012; Zimmerman, 1990; Zimmerman \& Cleary, 2009).

\section{Adaptive Help Seeking}

Over the last 30 years, educational researchers have investigated academic help seeking as an effective strategy of self-regulated learning (Karabenick \& Newman, 2006; Nelson-Le Gall, 1981), connected with higher levels of engagement, motivation, persistence, learning, and achievement (Karabenick \& Gonida, 2018). Initially, help seeking was examined as a complex metacognitive problem-solving skill, but research showed that, even though the cognitive capacities underlying help seeking improve across early adolescence, students' use of help seeking declines (Ryan et al., 2001). This apparent contradiction led to the recognition that help seeking, as a social transaction that involves costs and benefits, also depends on social skills and motivational resources (Newman, 2000). Subsequent research identified personal characteristics associated with help seeking, including perceived academic and social competence, mastery goal orientations, sense of belonging, and actual achievement.

Much of this work is social and ecological, in that many of the contextual factors that support students' motivation, engagement, and self-regulated learning (e.g., rules and norms, achievement goal structures, and interpersonal climate) have also been shown to have a positive effect on help seeking (Karabenick \& Dembo, 2011).
Research on help seeking focuses largely on individual and group differences, even though early conceptualizations were explicitly developmental (e.g., Nelson-Le Gall, 1985; Newman, 2000). For example, early work tied help seeking in school back to attachment processes in the family, where parents scaffold help seeking, and young children learn whether trusted others are available as sources of comfort and instrumental help.

\section{Emotion Regulation}

Although work on motivation and engagement has always incorporated students' emotions, only in the last 15 years or so have academic emotions been studied as topics in their own right (Pekrun \& Linnenbrink-Garcia, 2014). Within education, the study of emotion regulation, or the processes by which individuals modulate their emotional experience and expression, emerged from research on emotions in the classroom as well as from the large bodies of work focused on emotion regulation in adults (Gross, 1998) and children (Thompson, 2015). Education researchers have borrowed from models of emotion-focused coping that highlight the role of emotional reactions when dealing with stressors (Boekaerts, 2011; Boekaerts \& Pekrun, 2015) and from models of emotion generation in adults that identify points at which individuals can intentionally shape their emotions (Gross, 1998; Jacobs \& Gross, 2014). Although multiple adaptive and maladaptive emotion regulation strategies have been identified (see Table 1), few studies have examined their effects in the academic domain. At its most general, emotion regulation can be seen as a self-regulatory capacity, which may explain its hypothesized links to students' learning, motivation, engagement, and behavior problems (Boekaerts \& Pekrun, 2015; Jacobs \& Gross, 2014).

To date, educational perspectives on emotion regulation focus almost exclusively on individual differences. No developmental accounts have been suggested, despite the rich and extensive developmental database on emotion regulation outside the educational area (e.g., Thompson, 2015). Researchers draw on the larger motivational and educational literatures to suggest practices likely to support students' constructive emotion regulation, including the quality of teacher instruction and relationships, task assignments, grading practices, classroom goal structures, and socioemotional scaffolding and climate (Boekaerts \& Pekrun, 2015).

\section{Buoyancy}

Academic buoyancy refers specifically to students' everyday academic resilience - that is, to the set of behaviors that allow students to successfully navigate minor challenges and setbacks in school. Martin and Marsh (2009) differentiate buoyancy from students' reactions to more chronic stressors, although they point out that buoyancy should also strengthen students' ability to deal with major stressors more successfully (Martin, 2013). Many studies utilize cross-lagged designs to examine the predictors of changes in academic buoyancy, and some research has even considered potential reciprocal effects, but to date few investigations have traced age-graded shifts or trajectories of academic buoyancy across successive developmental periods.

Martin and Marsh's (2009) conceptualization considers a variety of contextual supports and self-system processes that give rise to buoyancy and, as a result, to outcomes such as academic engagement and achievement. These contextual supports span multiple 
settings and social partners and, when present, can promote academic buoyancy and positive educational outcomes. For example, students' relationships with teachers who provide responsive and effective feedback and support; school characteristics such as funding, class size, safety, or curriculum; and peer relationships have all been shown to contribute to students' academic buoyancy. Moreover, processes such as self-efficacy, self-esteem, and mastery orientation, as well as the ability to manage anxiety, have been considered central to students' capacity to successfully navigate everyday struggles in school (Datu \& Yuen, 2018). Each of these predictors represent malleable factors that can be targeted within classroom practices and interventions (Putwain et al., 2019), and the ability to bounce back following setbacks has been shown to be important in its own right, over and above the effects of academic coping (Putwain et al., 2012) or other constructs such as adaptability or prior motivation (Holliman et al., 2018).

\section{Grit, Tenacity, Academic Perseverance, and Productive Persistence}

Discussions of students' persistence in the face of academic challenges have arisen in conjunction with recent attention to "noncognitive skills" and "21st century skills" (Cunha \& Heckman, 2007; National Research Council, 2012). In fact, several publications on similar topics are summarized in an integrative report produced in collaboration with the U.S. Department of Education (SRI International, 2018). Among the publications in that report are reviews of the literature detailing how to support academic tenacity (Dweck et al., 2014) and academic perseverance (Farrington et al., 2012; see Table 1 for definitions), as well as interventions such as the productive persistence component of the Carnegie Pathways initiative (Silva \& White, 2013). Many of these approaches draw on the construct of grit (Duckworth et al., 2007), defined as "perseverance and passion for long-term goals" over the course of years, while also highlighting the actions (such as self-control and anxiety reduction) students use to persevere in the short term. As implied by terms like "productive persistence," these conceptualizations point out that motivation to persevere does not benefit students unless it is accompanied by appropriate strategies, skills, and knowledge, especially in interventions designed to address well-documented systematic barriers underlying current achievement gaps.

These perspectives incorporate a wide variety of personal factors as key resources that support persistence, including students' beliefs about their capacities and connectedness to others (and implicit beliefs about their malleability; see Yeager \& Dweck, 2012), and motivational orientations, such as the nature of students' academic goals and their beliefs that academic work is relevant and of value. Moreover, these conceptualizations also highlight the important role of social contexts in fostering such resources and discuss specific pedagogical and institutional supports that can promote students' tenacity and success.

\section{Integrative Framework for the Study of Motivational Resilience}

Taken together, eight of the approaches summarized here suggest several steps in the process of motivational resilience and vulnerability (see Figure 1). The ninth area of work, academic resilience, provides a larger frame for all of these processes (see Figure 2). All eight approaches focus on patterns of action, that is, emotions and behaviors students actually undertake on the ground while they are dealing with academic difficulties in their daily lives. Some conceptualizations consider steps earlier in the process by pointing out that students contribute to the academic problems they encounter by deciding whether to take on or avoid academic challenges (depicted as a first step in Figure 1). Some approaches also note that students run into problems during their ongoing engagement with academic work, and so suggest that patterns of engagement and disaffection already predispose students to resilience or vulnerability. For these theories, the process incorporates ongoing engagement and disaffection as a second step. As gauges of motivation, these states represent the overall energy, purpose, and determination students invest while working on their academic tasks.

All eight strands of research incorporate the third step, initiated when students encounter difficulties in their schoolwork. Although each conceptualization highlights its own set of academic problems (see Table 2), together they represent a wide range of anticipated and experienced academic difficulties, including challenges, obstacles, setbacks, confusion, and failure. Only a few conceptualizations focus explicitly on the fourth step - the reactivity that academic problems can provoke. These are included as "stress reactivity" in theories of coping and as "emotional reactivity" in theories of emotion regulation. Both of these perspectives suggest that, during stressful episodes, students must deal not only with the academic problem itself but also with their own reactions to it.

Several strands of research depict the fifth step, describing the specific actions students actually take to deal with academic stressors and the reactivity they generate. These include theories of mastery versus helplessness, academic coping, self-regulated learning, adaptive help seeking, and emotion regulation. Although each focuses on its own families of processes (see Table 1), some highlighting adaptive strategies (e.g., help seeking) and some incorporating unproductive responses (e.g., escape), there is still considerable overlap among approaches in their discussions of the ways students can regulate their actions under stress. In fact, together, these theories begin to identify a profile or repertoire of constructive strategies and maladaptive alternatives. Several strands of research also directly examine the sixth step, which includes processes of "bounce back" or "rebound," referred to alternatively as buoyancy, re-engagement, tenacity, academic perseverance, or productive persistence. And a few areas of study go on to posit a seventh step, in which rebound (or giving up) feeds forward into subsequent preference for challenge (or avoidance of difficult tasks) and ongoing engagement (or disaffection). The use of the umbrella terms motivational resilience and vulnerability implies that all of these processes, including task selection, engagement, reactivity, regulation, persistence, and rebound, can be considered parts of a larger system that work together to mutually entrain each other over time.

\section{External Dynamics of Motivational Resilience and Vulnerability}

Because of the importance of motivational resilience and its potential to support learning and positive growth, researchers from all these areas have been keen to understand the personal, pedagogical, curricular, and social factors that promote (or undermine) its development. To distinguish these factors from patterns of action inside processes of motivational resilience proper (depicted in Figure 1), 


\section{PROCESSES of MOTIVATIONAL RESILIENCE and VULNERABIITY}

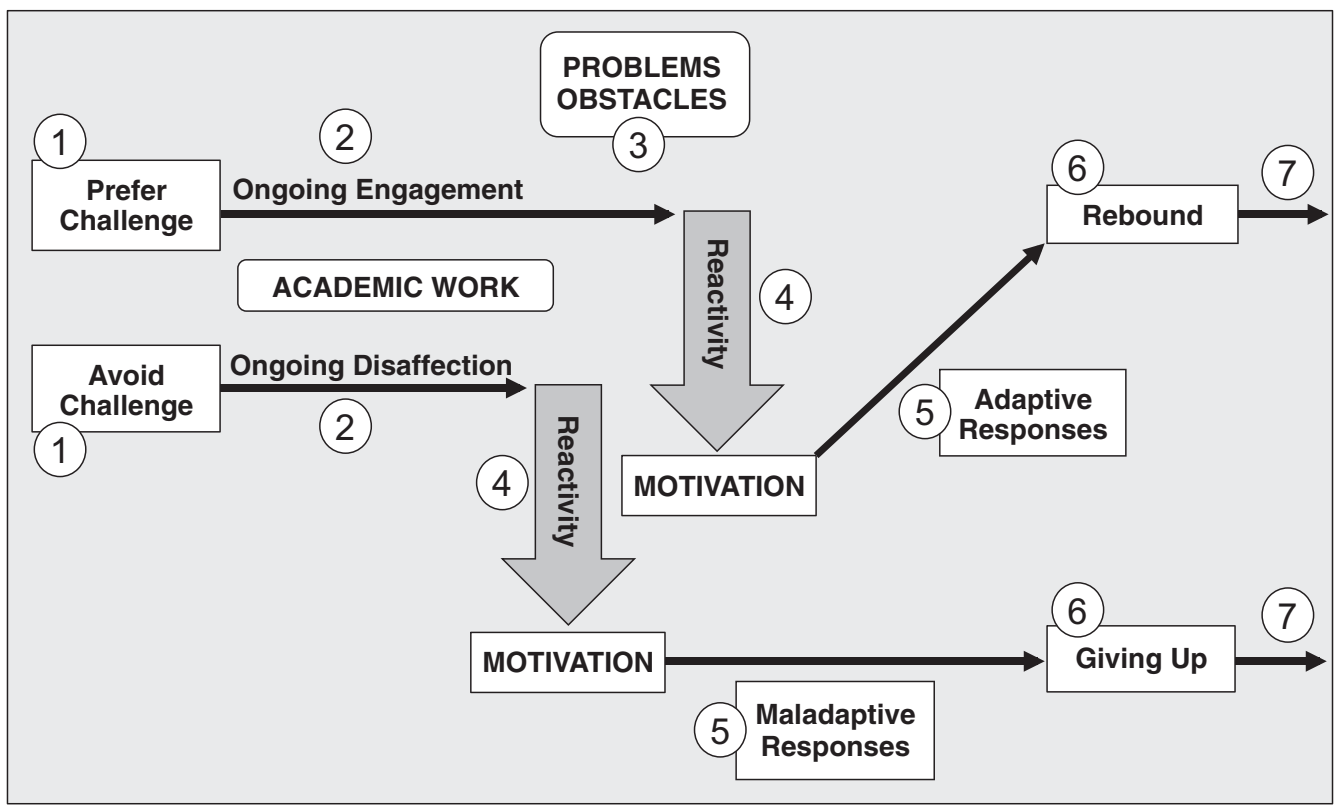

Figure I. An Episodic Account of Seven Steps in the Internal Dynamics of Motivational Resilience and Vulnerability.

Note. A 7-step process in which: (I) Students either undertake or avoid challenging academic tasks and then (2) During ongoing engagement and disaffection with academic work, students (3) Encounter problems or obstacles that exert a downward pressure on their motivation and (4) Generate reactivity. In turn, through (5) A variety of regulatory and motivational processes, students either (6) Rebound and re-engage in learning activities or they withdraw, forfeiting opportunities for learning and satisfaction, which (7) Feeds forward into subsequent episodes of task choice and engagement.

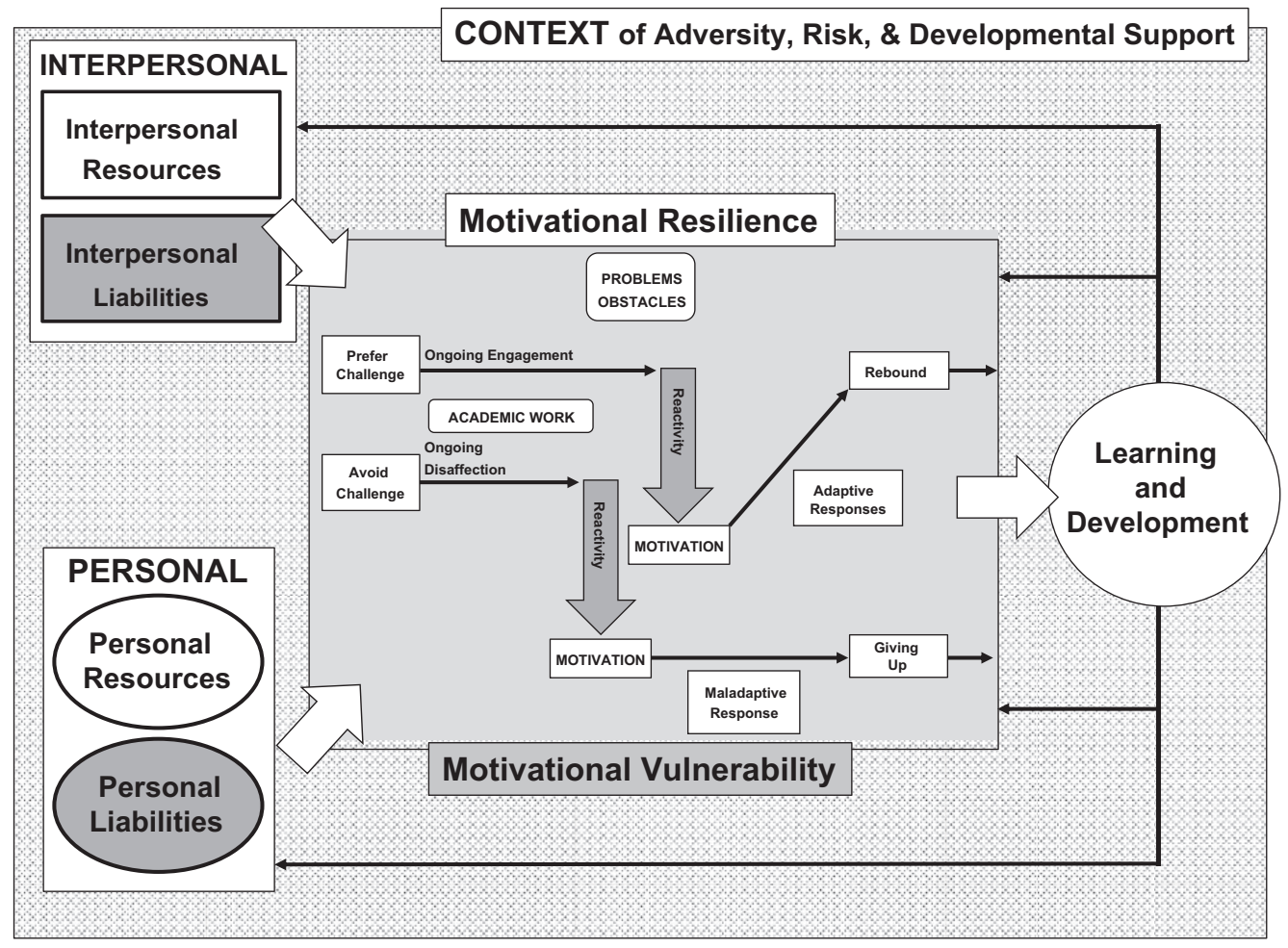

Figure 2. A Model of the External Dynamics of Motivational Resilience.

Note. Personal and interpersonal resources and liabilities shape the functioning of the processes of resilience and vulnerability, which in turn contribute to subsequent learning and development, all within a higher order context of adversity, risk, and developmental supports. 
we refer to them as "external dynamics," which describe the antecedents and consequences of motivational resilience as well as the higher order contexts of risk, adversity, and developmental support within which all these processes unfold, and that shape their shortand long-term functioning (as pictured in Figure 2; Pitzer \& Skinner, 2017). Although any personal or interpersonal predictor of motivation and engagement can play a role in the development of this system, we are particularly interested in those that make a difference on the ground when students encounter academic challenges and problems. These are the motivational and regulatory resources (both personal and interpersonal) students draw on when their automatic, ongoing interactions with schoolwork are disrupted by academic difficulties. These resources are the central constructs of theories that focus on growth mindsets, self-efficacy, learned helplessness, self-determination, and social support and are highlighted in theories of coping, emotion regulation, and buoyancy. Theories of external dynamics involve explanatory mechanisms that begin to identify targets for intervention.

\section{Common Ground and Complementary Strengths}

In this article, we have highlighted the many ways in which theories and research from these disparate areas share a common focus on trying to understand how students deal constructively with challenges and problems in their academic work. Although these approaches differ in several key respects, such differences actually confer a cumulative advantage when trying to create a comprehensive framework: They allow the weaknesses or gaps of one approach to be shored up by the strengths of others. For example, work on coping identifies the broadest range of strategies students can use to deal with academic stressors, but discussion of any one strategy tends to be thin. However, other areas like self-regulated learning and adaptive help seeking focus on specific strategies, and so provide more detail and depth about these families of responses. At the same time, these latter approaches focus narrowly on only one set of adaptive strategies, and so can benefit from research that describes a range of alternative or synergistic positive and negative responses. Perspectives also differ in the underlying psychological processes they highlight as contributors to resilience. Some focus on skills (e.g., problem-solving), some on will (e.g., regulatory theories), some on emotion and attention (e.g., emotion regulation), some on cognitive underpinnings (e.g., helplessness), some on metacognitive capacities (e.g., help seeking), and some on motivation (e.g., re-engagement). Each of these conceptualizations depicts an important part of the story, but only a part - since it is likely that all of these psychological processes are activated when students run into trouble, and students must call on and coordinate all of these processes when their automatic responses are challenged or overwhelmed.

Gaps in the process accounts of particular approaches can be filled using the substantive contributions of others. For example, research on ongoing engagement provides a rich, higher order motivational and emotional context within which to consider episodes of resilience but has little to say about exactly what happens to students' engagement when they run into difficulties or challenges. This step in the process, however, is the explicit focus of work on strategies of coping, self-regulated learning, and emotion regulation. Theories of coping and emotion regulation in turn have their own blind spots, in that they often have difficulty determining which of these families of responses are "good news" and "bad news." However, this determination can be aided by considering the effects these responses have on students' subsequent buoyancy, tenacity, and re-engagement. These latter approaches, in turn, tend to focus on these states as individual characteristics, which means that they can be enriched by approaches focusing on the regulatory and coping processes that give rise to them.

\section{Social Contexts and Development}

All conceptualizations presented here highlight key personal resources that shape motivational resilience and vulnerability but often devote less attention to the role of contextual factors. However, taken together, these approaches begin to paint a fuller picture of the complex social ecology and its pedagogy, curriculum, discipline, climate, and interpersonal relationships. Collectively, discussions of interpersonal factors help shift theories from a trait or person-centered view of motivational resilience to one that recognizes that these malleable processes are fully contextualized in the social worlds of home, school, and peers. Research on academic resilience is especially helpful in providing a view of the higher order societal and contextual adversity, and risk and protective factors that shape the workings of all of the lower order processes.

Common ground and complementarity are also both apparent with respect to development. All of these lines of work provide process-oriented accounts and examine explanatory factors that produce changes in different steps in these processes. However, few are explicitly "big D" developmental. Notable exceptions are represented by research on self-regulated learning and emotion regulation, which has an entire body of research dedicated to the study of its age-graded changes and shifts (e.g., Thompson, 2015), and by classic research on resilience (Masten, 2014), which has the explicit goal of examining how adversity shapes differential pathways of short- and long-term development. Rich developmental literatures on many aspects of regulation (e.g., Wigfield et al., 2011) hold promise in helping researchers interested in motivational resilience consider the constraints and opportunities inherent in each developmental period, as well as the changing roles that social partners must play if these processes are to develop along healthy pathways (e.g., Skinner \& Zimmer-Gembeck, 2016). In the same vein, theories and methodologies for studying "big R" academic resilience can inspire researchers examining everyday resilience to consider individual differences in students' actions as markers or snapshots taken from the larger movie of their academic development.

\section{Future Research}

Even if the components depicted in Figure 1 have largely been studied separately up to now, an umbrella construct like motivational resilience reminds researchers that these processes are all in play on the ground when students actually encounter challenges and obstacles in their schoolwork. Investigations that can capture this rich complexity will advance the study of all of these processes. A focus on patterns of action anchors research in this emerging area in the here and now of students' academic struggles, but the integration of work from these many areas suggests that multiple underlying processes (cognitive, metacognitive, volitional, motivational, emotional, attentional) are working together to give rise to these different ways of responding to problems. Up to now, researchers 
have sometimes been surprised that students decline to exercise constructive actions of which they are capable (e.g., adaptive help seeking) or that students find it difficult to translate their motivations into effective actions (e.g., coping). Some of these questions may be answered by studies that consider how all of these processes work together, and how breakdowns in the functioning of any one of these capacities may be sufficient to scuttle constructive patterns of action under stress.

Such a wholistic perspective can also guide developmental studies, encouraging researchers to trace the pathways of all of these underlying processes back to earlier developmental periods when habits of mind and action were first taking shape. These many processes are like threads of different colors, each of which has its own timetables and supportive conditions, but that are all recruited each time a student is called upon to coordinate them in response to demands and difficulties with their schoolwork. The discovery of these age-graded processes will allow researchers to identify the developmental tasks that must be successfully negotiated at each age if students are to develop the capacity to deal constructively with the academic challenges that await them.

The same dual focus that researchers bring to patterns of actions (as a current system with ties to the past) will be helpful in identifying the personal and interpersonal resources that support the development of motivational resilience. The study of the exact supports-curricular, pedagogical, organizational, socioemotional-that scaffold constructive patterns of action in the moment can be supplemented with a focus on the past. For example, it may be that the effects of any interpersonal supports teachers can provide a student in the present are conditional on the extent to which the teacher has already cultivated a close and trusting relationship with that student in the past. Or on the extent to which the classroom has already been experienced as a place where mistakes and setbacks indicate that learning is in progress, and not that students' abilities are on display. As researchers work their way up to the higher order contexts that engulf all these processes, a sharper focus on the primary interpersonal supports for students' motivational resilience (namely, teachers, schools, classmates, friends, peers, parents, and families) should bring attention to the demands and resources in the lives of these social partners, as conditions that impact how attuned they can be to students' academic struggles and how much support they can provide. A major challenge to our current educational system results from the fact that the students who encounter the most stresses and problems are likely to belong to subgroups who have access to the fewest institutional and social resources to support them (Spencer, 2006).

\section{Implications for Educational Practice and Intervention}

Just as concepts of motivational resilience can anchor researchers' activities, so too can they anchor the work of teachers and schools. Many facets of motivational resilience, precisely because they are patterns of action, are visible to teachers - if they have the eyes to see. Figures 1 and 2 may be helpful in creating mental working models, not only for researchers but also for teachers, highlighting the kinds of responses that students show in their classrooms - the adaptive help seeking, problem-solving, and re-engagement of resilient responses, as well as the passivity, concealment, resentment, and disruption that may signal motivational vulnerability. A crucial part of such mental models is the view that these patterns of action do not represent character traits; instead, they are malleable states that reveal students' past experiences with challenge as well as their current capacities to deal constructively with academic problems and frustrations. A focus on external dynamics highlights the essential role of teachers and other adults in these processes, but it also reminds interventionists and schools that teachers themselves are embedded in systems, and for them to have the time, leeway, and energy to focus on monitoring and responding to individual students, teachers themselves must have adequate supports from their own higher order contexts.

Taken together, work on motivational resilience and vulnerability sends a strong message to educators that the only way students can develop resilience is through practice, that is, through the hard work of wrestling with academic setbacks. Of course, teachers should be attuned to students' developmental readiness and their current states, but "resilience muscles" can only be strengthened through ongoing participation in the fray of academic challenges and obstacles that are an inherent part of learning. This means that students should not be protected from everyday academic stressors and demands; instead, teachers can intentionally "dose" them with just-manageable challenges while providing the kinds of pedagogical and interpersonal supports that allow students to figure out how to box their way through. The overall model depicted in Figure 2 suggests multiple points for intervention-promoting ongoing engagement, reducing emotional reactivity, adding strategies of self-regulated learning and coping, learning to effectively regulate emotions. Explanatory theories of the external dynamics of motivational resilience begin to highlight potential intervention levers, but also point out that all the necessary supporting processes must be up and running if students are to constructively deal with, recover from, and learn from such experiences. And students must have repeated practice if these episodes are to result in the development of resilience strategies and resources. The feed forward and feedback loops pictured in Figure 2 suggest that if students' social ecologies (i.e., their schools, families, and peer groups) can help them to tackle challenging learning activities and build their motivational resilience, then these processes will continue to intervene on their own behalf, forming virtuous cycles that contribute to students' long-term development and educational success.

\section{Funding}

The author(s) received no financial support for the research, authorship, and/or publication of this article.

\section{ORCID iD}

Ellen A. Skinner (D) https://orcid.org/0000-0002-1111-229X

Nicolette Rickert (D) https://orcid.org/0000-0001-6584-4413

\section{References}

Aldwin, C. M. (2007). Stress, coping, and development: An Integrative perspective (2nd ed.). Guilford Press.

Appleton, J. J., Christenson, S. L., \& Furlong, M. (2008). Student engagement with school: Critical conceptual and methodological issues of the construct. Psychology in the Schools, 45, 369-386.

Blondal, K. S., \& Adalbjarnardottir, S. (2012). Emotional and behavioral disengagement from school and school dropout. Scandinavian Journal of Educational Research, 56, 85-100.

Boekaerts, M. (2011). Emotions, emotion regulation, and self-regulation of learning. In B. J. Zimmerman \& D. H. Schunk (Eds.), Handbook of self-regulation of learning and performance (pp. 408-425). Routledge. 
Boekaerts, M., \& Pekrun, R. (2015). Emotions and emotion regulation in academic settings. In L. Corno \& E. M. Anderman (Eds.) Handbook of educational psychology (3rd ed., pp. 76-90). Routledge.

Christenson, S. L., Reschly, A. L., \& Wylie, C. (2012). Handbook of research on student engagement. Springer Science.

Cunha, F., \& Heckman, J. J. (2007). The technology of skill formation. American Economic Review, 97(2), 31-47.

Datu, A. D., \& Yuen, M. (2018). Predictors and consequences of academic buoyancy: A review of literature with implications for educational psychological research and practice. Contemporary School Psychology, 22, 207-212.

Duckworth, A. L., Peterson, C., Matthews, M. D., \& Kelly, D. R. (2007). Grit: Perseverance and passion for long-term goals. Personality Processes and Individual Differences, 92, 1087-1101.

Dweck, C. S. (1986). Motivational processes affecting learning. American Psychologist, 41, 1040-1048.

Dweck, C. S. (2008). Mindset: The new psychology of success. Random House.

Dweck, C. S., \& Leggett, E. L. (1988). A social-cognitive approach to motivation and personality. Psychological Review, 95, 256-273.

Dweck, C. S, Walton, G. M., \& Cohen, G. L. (2014). Academic tenacity: Mindsets and skills that promote long-term learning. Bill \& Melinda Gates Foundation.

Dweck, C. S., \& Wortman, C. B. (1982). Learned helplessness, anxiety, and achievement motivation: Neglected parallels in cognitive, affective, and coping responses. In H. W. Krohne \& L. Laux (Eds.), Achievement, stress, and anxiety (pp. 93-125). Hemisphere Publishing.

Fantuzzo, J., LeBoeuf, W., Rouse, H., \& Chen, C. C. (2012). Academic achievement of African American boys: A city-wide, community-based investigation of risk and resilience. Journal of School Psychology, 50(5), 559-579.

Farrington, C. A., Roderick, M., Allensworth, E., Nagaoka, J., Keyes, T. S., Johnson, D. W., \& Beechum, N. O. (2012). Teaching adolescents to become learners: The role of noncognitive factors in shaping school performance - A critical literature review. University of Chicago Consortium on Chicago School Research.

Fredricks, J. A., Blumenfeld, P. C., \& Paris, A. H. (2004). School engagement: Potential of the concept, state of the evidence. Review of Educational Research, 74, 59-109.

Gross, J. J. (1998). The emerging field of emotion regulation: An integrative review. Review of General Psychology, 2(3), 271-299.

Harter, S. (1981). A model of mastery motivation in children: Individual differences and developmental change. In W. A. Collins (Ed.), The Minnesota symposia on child psychology (Vol. 14, pp. 215-255). Erlbaum.

Holliman, A. J., Sheriston, L., Martin, A. J., Collie, R. J., \& Sayer, D. (2018). Adaptability: Does students' adjustment to university predict their mid-course academic achievement and satisfaction? Journal of Further and Higher Education, 43, 1444-1455. https://doi. org/10.1080/0309877X.2018.1491957

Jacobs, S. E., \& Gross, J. J. (2014). Emotion regulation in education. In R. Pekrun \& L. Linnenbrink-Garcia (Eds.), International handbook of emotions in education (pp. 183-217). Taylor \& Francis.

Janosz, M., Archambault, I., Morizot, J., \& Pagani, L. S. (2008). School engagement trajectories and their differential predictive relations to dropout. Journal of Social Issues, 64, 21-40.

Jennings, K. D., \& Dietz, L. J. (2003). Mastery motivation and goal persistence in young children. In M. H. Bornstein, L. Davidson, C. L. Keyes, \& K. A. Moore (Eds.), Well-being: Positive development across the life course (pp. 295-309). Taylor \& Francis.
Jimerson, S. R., Campos, E., \& Greif, J. L. (2003). Towards an understanding of definitions and measures of school engagement and related terms. The California School Psychologist, 8, 7-28.

Karabenick, S. A., \& Dembo, M. H. (2011). Understanding and facilitating self-regulated help seeking. New Directions for Teaching and Learning, 2011(126), 33-43.

Karabenick, S. A., \& Gonida, E. N. (2018). Academic help seeking as a self-regulated learning strategy: Current issues, future directions. In D. H. Schunk \& J. A. Greene (Eds.), Handbook of self-regulation of learning and performance (2nd ed., Chapter 27, pp. 421-433). Routledge.

Karabenick, S. A., \& Newman, R. S. (Eds.). (2006). Help seeking in academic settings: Goals, groups, and contexts. Lawrence Erlbaum.

Li, Y., \& Lerner, R. M. (2011). Trajectories of school engagement during adolescence: Implications for grades, depression, delinquency, and substance use. Developmental Psychology, 47, 233-247.

Mark, S. F. (1983). To succeed or not to succeed: A critical review of issues in learned helplessness. Contemporary Educational Psychology, 8, 1-19.

Martin, A. J. (2009). Motivation and engagement across the academic life span. Educational and Psychological Measurement, 69, 794-824.

Martin, A. J. (2013). Academic buoyancy and academic resilience: Exploring "everyday" and "classic" resilience in the face of academic adversity. School Psychology International, 34(5), 488-500.

Martin, A. J., \& Marsh, H. W. (2006). Academic resilience and its psychological and educational correlates: A construct validity approach. Psychology in the Schools, 43, 267-281.

Martin, A. J., \& Marsh, H. W. (2009). Academic resilience and academic buoyancy: Multidimensional and hierarchical conceptual framing of causes, correlates and cognate constructs. Oxford Review of Education, 35(3), 353-370.

Masten, A. S. (2007). Resilience in developing systems: Progress and promise as the fourth wave rises. Development and Psychopathology, 19(3), 921-930.

Masten, A. S. (2014). Ordinary magic: Resilience in development. Guilford.

National Research Council. (2012). Education for life and work: Developing transferable knowledge and skills in the 21st century. The National Academies Press.

Nelson-Le Gall, S. (1981). Help seeking: An understudied problem-solving skill in children. Developmental Review, 1, 224-226.

Nelson-Le Gall, S. (1985). Help seeking behavior in learning. Review of Research in Education, 12, 55-90.

Newman, R. S. (2000). Social influences on the development of children's adaptive help seeking: The role of parents, teachers, and peers. Developmental Review, 20, 350-404.

Pekrun, R., \& Linnenbrink-Garcia, L. (Eds.). (2014). International handbook of emotions in education. Taylor \& Francis.

Pitzer, J. R., \& Skinner, E. A. (2017). Predictors of changes in students' motivational resilience over the school year: The roles of teacher support, self-appraisals, and emotional reactivity. International Journal of Behavioral Development, 41, 15-29.

Putwain, D. W., Connors, L., Symes, W., \& Douglas-Osborn, E. (2012). Is academic buoyancy anything more than adaptive coping? Anxiety, Stress and Coping, 25, 349-358.

Putwain, D. W., Gallard, D., \& Beaumont, J. (2019). A multi-component wellbeing program for upper secondary students: 
Effects on wellbeing, buoyancy, and adaptability. School Psychology International, 40, 49-65.

Ryan, A. M., Pintrich, P. R., \& Midgley, C. (2001). Avoiding seeking help in the classroom: Who and why? Educational Psychology Review, 13(2), 93-114.

Schunk, D. H., \& Greene, J. A. (2017). Handbook of self-regulation of learning and performance. Routledge.

Silva, E., \& White, T. (2013). Pathways to improvement: Using psychological strategies to help college students master developmental math. Carnegie Foundation for the Advancement of Teaching.

Skinner, E. A., \& Pitzer, J. (2012). Developmental dynamics of engagement, coping, and everyday resilience. In S. Christenson, A. Reschly, \& C. Wylie (Eds.), Handbook of research on student engagement (pp. 21-45). Springer Science.

Skinner, E. A., \& Saxton, E. A. (2019). The development of academic coping in children and youth: A comprehensive review and critique. Developmental Review, 53, 100870.

Skinner, E. A., \& Zimmer-Gembeck, M. J. (2007). The development of coping. Annual Review of Psychology, 58, 119-144.

Skinner, E. A., \& Zimmer-Gembeck, M. J. (2016). The development of coping: Stress, neurophysiology, social relationships, and resilience during childhood and adolescence. Springer.

Spencer, M. B. (2006). Phenomenology and ecological systems theory: Development of diverse groups. In W. Damon, \& R. Lerner (Eds.), Handbook of child psychology, Vol. 1: Theoretical models of human development (6th ed., Chapter 15, pp. 829-893). Wiley.

SRI International. (2018). Promoting grit, tenacity, and perseverance: Critical factors for success in the 21st century. SRI International. https:/www.sri.com/work/publications/ promoting-grit-tenacityand-perseverance-critical-factors-success-21st-century.

Thomas, A. (1989). Reviews of research: Ability and achievement expectations: Implications of research for classroom practice. Childhood Education, 65, 235-241.

Thompson, R. A. (2015). Relationships, regulation, and early development. In R. M. Lerner (Series Ed.) \&M. Lamb (Volume Ed.), Handbook of child psychology and developmental science: Vol.3. Socioemotional processes (7th ed., pp. 201-246). Wiley.

Tudor, K. E., \& Spray, C. M. (2017). Approaches to measuring academic resilience: A systematic review. International Journal of Research Studies in Education, 7(4), 41-61.

Upadyaya, K., \& Salmela-Aro, K. (2013). Development of school engagement in association with academic success and well-being in varying social contexts: A review of empirical research. European Psychologist, 18, 136-147.

Wang, M. C., Haertel, G. D., \& Walberg, H. J. (1994). Educational resilience in inner cities. In M. C. Wang \& E. W. Gordon (Eds.), Educational resilience in inner-city America: Challenges and prospects. Lawrence Erlbaum.

Waxman, H., Gray, J., \& Padron, Y. (2003). Review of research on educational resilience. Center for Research on Education, Diversity, and Excellence.

Wigfield, A., Eccles, J. S., Fredricks, J. A., Simpkins, S., Roeser, R., \& Schiefele, U. (2015). Development of achievement motivation and engagement. In R. M. Lerner (Series Ed.) \& M. Lamb (Volume Ed.), Handbook of child psychology and developmental science (7th ed., Vol. 3., Socioemotional processes pp. 657-700). New York: John Wiley.

Wigfield, A., Klauda, S. L., \& Cambria, J. (2011). Influences on the development of academic self-regulatory processes. In D. H. Schunk (Ed.), Handbook of self-regulation of learning and performance (pp. 33-48). Routledge.

Wolchik, S. A., \& Sandler, I. N. (Eds.). (1997). Handbook of children's coping: Linking theory and intervention. Plenum.

Wolters, C. A., \& Taylor, D. J. (2012). A self-regulated learning perspective on student engagement. In S. Christenson, A. Reschly, \& C. Wylie (Eds.), Handbook of research on student engagement (pp. 635-651). Springer.

Wright, M. O., Masten, A. S., \& Narayan, A. J. (2013). Resilience processes in development: Four waves of research on positive adaptation in the context of adversity. In S. Goldstein \& R. B. Brooks (Eds.), Handbook of resilience in children (2nd ed., pp. 15-37). Kluwer Academic/Plenum.

Yeager, D. S., \& Dweck, C. S. (2012). Mindsets that promote resilience: When students believe that personal characteristics can be developed. Educational Psychologist, 47, 302-314.

Zimmerman, B. J. (1990). Self-regulated learning and academic achievement: An overview. Educational Psychologist, 25, 3-17.

Zimmerman, B. J., \& Cleary, T. J. (2009). Motives to self-regulate learning: A social cognitive account. In K. Wentzel \& A. Wigfield (Eds.), Handbook of Motivation at School (pp. 247-264). New York, NY: Routledge.

Zusho, A. (2017). Toward an integrated model of student learning in the college classroom. Educational Psychology Review, 29, 301-324. 